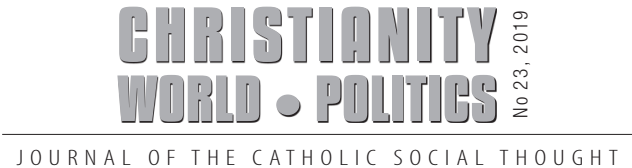

Marguerite A. Peeters

Institute for Intercultural Dialogue Dynamics, Belgium

\title{
The 2016-2063 Sexual and Reproductive Health and Reproductive Rights Neo-Colonizing Plan for Africa
}

\begin{abstract}
Abstrakt: Artykuł przedstawia argumenty wskazujące na prowadzenie wobec Afryki polityki zmierzającej do zmiany percepcji kwestii dotyczących etyki seksualnej. W imię umacniania bezpieczeństwa, zrównoważonego rozwoju czy wolności postulowane są rozwiązania zmierzające do popierania aborcji, stosowania środków antykoncepcyjnych zapłodnienia in vitro, sterylizacji czy edukacji seksualnej. Można sądzić, że kraje wysoko rozwinięte usiłują narzucić krajom ubogim politykę ludnościową, sprzeczną z zasadami etyki i prawami człowieka.
\end{abstract}

Słowa kluczowe: Afryka, ONZ, prawa reprodukcyjne, zdrowie reprodukcyjne

Abstract: The article presents the arguments demonstrating that Africa is subjected to the politics aimed at changing the perception of the issues concerning sexual ethics. In the name of improving security, sustainable development or freedom, some legal solutions are proposed, aimed at supporting abortion, using contraceptives, in vitro fertilization, sterilization or sexual education. One might think that developed countries are trying to impose on poor countries population politics which contradicts the principles of ethics and human rights.

Keywords: Africa, UN, reproductive rights, reproductive health

\section{Introductory remarks}

A silent drama keeps on unfolding and rapidly gaining momentum in developing countries, first and foremost in Africa, in the name of soft or human security, sustainable development, democratization, liberty, equality and human rights. Global governance is enforcing the agenda of the 1994 Fourth World Conference on Population and Development, the Cairo conference, in Africa more forcefully 
than in any other continent: sexual and reproductive health and reproductive rights (SRH and RR).

SRH and RR, which have become, in 2015, the agenda of the Sustainable Development Goals - the "framework" of international cooperation until 2030, have been fully integrated in Panafrican development policy frameworks since the inception of the African Union in 2002, and until 2063.

SRH and RR activists are all the more determined to "join forces and redouble efforts" [Maputo Plan: 11] in Africa than the UN predicts that the African population will represent $40 \%$ of the global population by 2100 [WPP 2017]. These estimates take into account the drastic measures set in place and implemented by the population establishment to reduce African fertility rates: their own prediction is that by the end of the century, the African fertility rate will have dropped from its current rate of $4.7 \%$ to $2.1 \%$.

Population concerns, when real, need to be addressed in respect for the family as the basic unit of society, and for the right and duty of a "responsible transmission of life" [Gaudium et spes: 51] which respects the biological processes. Governments must enact "laws which will assist families" and educate "the people wisely so that the moral law and the freedom of the citizens are both safeguarded" [Paul VI 1968: 23].

Africa is in a life and death combat. The sense of the family, motherhood, fatherhood, brotherhood, children, the sacredness of life defines the African soul. The strength of African cultures, however, contrasts with the weakness of African political institutions and their permeability to foreign, culturally and morally destructive, agendas. Dramatically enough, African institutionalization has been hijacked and does not go the way of representing the African peoples and cultures. But how could it? Representation has disappeared from the political vocabulary and practice of the West.

The 2017 UN population prospects: Africans to represent more than $40 \%$ of the world population by 2100

The 2017 report of the UN Department of Economic and Social Affairs (DESA)'s Population Division, "World Population Prospects, the 2017 revision"1, contends

1 Having no means to verify the accuracy of DESA's figures on the one hand, and keeping in mind the unchanged population control objectives of the UN since the 1960s on the other, we invite our readers to a certain prudence in the assessment of the demographic data and projections we present in this article. 
that the 2017 population of Africa (1.256 billion) represents $17 \%$ of the world's current population (7.55 billion), almost twice that of Europe (742 million), and three and a half times that of North America (361 million). In 1950, by contrast, the African population (221 million) was about half the European population; it was then only slightly over the size of the North American population.

According to DESA's medium-variant demographic projection, the African population will have grown to 4.468 billion by the end of this century. In 2100, it will represent more than $40 \%$ of the world's projected 11.184 billion. It will then be almost seven times that of Europe (projection of 653 million in 2100) and nine times that of North America (499 million). In the meantime, the population of Asia (4.504 billion in 2017) will only have increased by less than 300 million (4.78 in 2100): Asian population is projected to start decreasing by mid-century. Hence "beyond 2050, Africa will be the main contributor to global population growth" [WPP 2017: 3].

"More than half of the anticipated growth in global population between now and 2050 is expected to occur in Africa" [WPP 2017: 3]. Among the ten countries accounting collectively for more than half the projected world population increase, six are African: Nigeria, DRC, Ethiopia, Tanzania, Uganda and Egypt. Over the same 2017-2050 period, "the population of 26 African countries are projected to reach at least double their current size. For six African countries, the populations are projected to increase by 2100 to more than five times their current size: Angola, Burundi, Niger, Somalia, Tanzania and Zambia” [WPP 2017: 13].

The projected population growth of Africa in the $21^{\text {st }}$ century is attributed to several factors. First, Africa currently "has the youngest age distribution of any region": "children under age 15 account for 41 per cent of the population in 2017"; "young persons aged 15 to 24 account for an additional 19 per cent" [WPP 2017: 10]. Africa, secondly, is the continent where fertility levels are highest. "Of the 22 countries with relatively high levels of fertility in the most recent period, 20 are found in Africa and 2 in Asia" [WPP 2017: 6]. What DESA calls "the adolescent birth rate" (births per 1,000 women aged 15-19) “in 2010-2015 was highest in Africa, at 99 per 1,000 women" [WPP 2017: 14]. Thirdly, of course, Africa's contraceptive prevalence rate 2 is the lowest among the regions of the world. According to the Maputo Plan of Action, the continental rate is currently $28 \%$.

2 WHO defines contraceptive prevalence as "the percentage of women who are currently using, or whose sexual partner is currently using, at least one method of contraception, regardless of the method used. It is usually reported for married or in-union women aged 15 to 49 ". 


\section{Africa more than ever a priority target for the population establishment}

The DESA African population growth estimates just exposed above do take into account the projected results of the efforts of the population establishment to bring about "a substantial reduction of fertility levels in the near future" [WPP 2017: 4].

DESA projects, first, a significant fall of Africa's population growth rates: in recent years, reads the report, the population of Africa has had "the fastest growth among all regions, increasing at a rate of 2.6 per cent annually in 2010-2015". However, this rate "is beginning to fall and is projected to reach 1.8 in 2045-2050 and 0.66 in 2095-2100" [WPP 2017: 4].

DESA projects, secondly, a drastic fall of the continent's fertility rates: Africa's total fertility has already fallen "from 5.1 births per woman in 2000-2005 to 4.7 in 2010-2015" [WPP 2017: 12]. DESA's medium-variant projection "assumes that fertility in Africa will fall from around 4.7 births per woman in 2010-2015 to 3.1 in 2045-2050, reaching a level slightly above 2.13 in 2095-2100" [WPP 2017: 4]. The dramatic projected decline of Africa's fertility rate implies a dramatic and quick rise in Africa's contraceptive prevalence rate over the next decades.

Following its own logic, DESA concludes that "to achieve the substantial reductions in fertility projected in the medium-variant, it will be essential to support continued improvements in access to reproductive health care services, including family planning, especially in the least developed countries" [WPP 2017: 6].

Since the invention of modern contraception at the end of the 1950s, the population establishment has been going all out to control African population growth through coercive and morally illicit means. The new strategy they adopted in 1994, at the Fourth World Conference on Population, better known as the Cairo Conference, ruthlessly implemented ever since, will not only have as an effect the fall of fertility rates: it will produce an irreversible corruption of youth morality and cultural decadence.

In later sections of this article, we will expose how African health ministers and African heads of state integrated the full-fledged agenda of the population establishment and the global sexual revolution activists as a priority and at the very heart of continental and therefore national health policies until 2063. They did

3 As a reminder to our readers, 2.1 is the replacement level fertility in developed countries. 
it not out of their own will, but under the political and financial pressure of the globalist neo-colonizers.

In Laudato $\mathrm{Si}$, Pope Francis reaffirms the view of the Church on population issues: "Yet 'while it is true that an unequal distribution of the population and of available resources creates obstacles to development and a sustainable use of the environment, it must nonetheless be recognized that demographic growth is fully compatible with an integral and shared development.' To blame population growth instead of extreme and selective consumerism on the part of some, is one way of refusing to face the issues" [Francis 2015: 50].

\section{"Sexual and reproductive health" to potentially provoke full scale sexual revolution in Africa4}

A reminder of the content of the Cairo agenda imposed on Africa - of SRH and $\mathrm{RR}$, is in order here. In 1994, the Cairo conference provided the transnational agents of population control with an alleged global political consensus on a new demographic perspective called "sexual and reproductive health" and "reproductive rights". The UN called it a "globally normative consensus", a "framework".

Under the leading impulse of the International Planned Parenthood Federation (IPPF), Cairo operated a Copernican turn in global population policies: from the coercive, top-down demographic approach of the 60s, 70s and 80 s focused on numbers to an approach deceivingly qualified as "people-centred" and "focused on people's needs and rights".

The new perspective integrates population control goals but hides them within a broader agenda. Its moral, anthropological and cultural challenges are far more pernicious: the globalization of the western sexual revolution.

Incidentally, let us remark that some prolifers tend to equate sexual and reproductive health and reproductive rights plainly with "abortion". They need to be challenged to recognize that these euphemistic expressions in fact hide the whole spectrum of ingredients necessary to provoke a full-scale sexual revolution in developing countries. Let us spell these ingredients out:

4 This section draws on previous writings of the authors on sexual and reproductive health, inter alia on The globalization of the western cultural revolution, key concepts, operational mechanisms, chapter 3, and on Twenty Years of Sexual and Reproductive Health and Rights in Africa. 
1) "universal access" to the "full range" of contraceptives (including so-called "emergency contraception") [see: Suaudeau 2010] irrespective of age and marital status;

2) so-called "comprehensive sexual education", purely technical, not only amoral but immoral in its content;

3) AIDs prevention through such "sexual education" and condoms;

4) voluntary sterilization;

5) in vitro fertilization;

6) so-called "safe abortion" where it is legal - the idea being that, in order to be safe, it has to be legal: hence the pressure SRHR agents exercise on African governments to legalize abortion;

7) "sexual health", which is strategically fuzzy enough ${ }^{5}$ to open the door to the LGBT agenda.

By the early 1990s, population controllers and sexual revolution activists - chief among them the IPPF - had observed the undisputable efficiency of the western sexual revolution of the 1960s and 70s in reducing fertility, hence demographic growth in the West, especially in Europe ${ }^{6}$ : the revolution had provoked an unprecedented drop of the marriage rate and a massive breakdown of the family. The Cairo rationale was the following: provoking the sexual revolution in the developing world, particularly in Africa, would be far more efficient in terms of population control than the top-down institutional imposition of population policies practiced until then. By 1994, any open coercion, anything appearing "top-down" had become countercultural. The "freedom to choose" was the new paradigm.

Reproductive health is presented as "bottom-up": going through people themselves to achieve the geopolitical goal of population stabilization. But people, let us remark, are rooted in cultures, and the African culture is deeply rooted itself in a sense of the family, life, motherhood. The war then becomes cultural. The objective is to

5 The author was a journalist in the 1990s and interviewed the head of the WHO delegation at the Beijing conference, Dr. Hammad, asking her WHO's definition of "sexual rights". Hammad stated that we should not define sexual rights "so as to leave room to all the possibilities that you need". She also said that all the components of sexual rights, in all their dimensions, were in the Beijing document even if the expression "sexual rights" was not. See Peeters 1995.

6 The fact they will not recognize, however, is that the sexual revolution is the chief cause of Europe's demographic winter, now compensated by massive immigration. The previously mentioned DESA report reads that "between 2015 and 2050, the excess of deaths over births in Europe is projected to total 57 million, whereas the net inflow of international migrants is expected to be around 32 million" [WPP 2017: 16]. 
change the mentality of girls and women, hence the content of education, cultures and, to the extent possible, also religions to align them along the "freedom to choose" mindset. When girls and women succumb to brain-washing and start claiming their "right to choose", that is, their "right" to contraception, abortion, voluntary sterilization..., when young people start adopting "western sexual lifestyles", culture shifts to the side of SRHR agents, who have then won the war. For this strategic reason, SRHR agents are adamant at establishing "comprehensive sexuality education" and so-called "rights education" in school curricula in Africa.

Quite a few myths about reproductive health need to be debunked. To the extent it imposes western lifestyles on non-western cultures, reproductive health is not focused on women's needs and rights but on the demographic and economic interests, and cultural imperialism of a powerful clique of neo-colonizers. The allegedly non-coercive agenda is imposed through brainwashing and manipulation. The imposition is performed by the institutions of the population establishment: the agenda is not "people-centred".

\section{A "global framework" from 1994 to at least 2030: the source and powerhouse of pressures on Africa}

Before exposing how SRH and RR integrated Panafrican development policies, let us recall that the international community has repeatedly imprisoned itself, in an unbroken continuum, in the 1994 Cairo "framework" until at least 2030. Indeed, Panafrican frameworks refer themselves to those of global governance.

In spite of its profoundly ideological and therefore divisive content, the alleged SRHR "global consensus" has remained integral and unbroken ever since Cairo: this is evidence of the power wielded by its advocates within global governance. In fact the Cairo "consensus" was reinforced each time global governance shifted to a new "global framework" of international cooperation: more and stronger political, operational and financial partners have jumped on its bandwagon, more countries and more institutions have, under the relentless pressure of its agents, aligned themselves on its agenda and implemented it. SRHR are more integrated than ever into development policies. Yet the radical agenda, hidden in Cairo, has largely been uncovered. Countries and institutions have been able to check its contents against the destructive anthropological and cultural reality it has already brought about.

In 2001, the UN Millennium Development Goals (MDGs) became the new framework of international cooperation. Goal 5 included a target that read: "Achieve by 
2015, universal access to reproductive health." By 2015, SRHR agents estimated that the international community was far from having reached this goal.

The next "global development framework" for the 2016-2030 period, the Sustainable Development Goals (SDGs), integrate not only "reproductive health" but "sexual and reproductive health" and "reproductive rights": in other words, the full Cairo agenda; the SDGs go further than the MDGs. A target of SDG3, "Ensure healthy lives and promote well-being for all at all ages", reads: "By 2030, ensure universal access to sexual and reproductive health-care services, including for family planning, information and education, and the integration of reproductive health into national strategies and programmes". And SDG5, "Achieve gender equality and empower all women and girls", contains a similar target that reads: "Ensure universal access to sexual and reproductive health and reproductive rights as agreed in accordance with the Programme of Action of the International Conference on Population and Development and the Beijing Platform for Action and the outcome documents of their review conferences".

\section{The Global Strategy for Women's, Adolescents and Children's Health 2016-2030 - Survive, thrive, transform: operationalization strategy for SRHR}

The UN and its multistakeholder partners have taken the lead to implement, and monitor the implementation of, UN "consensuses", "global norms" and "development frameworks" ever since they were first adopted in the 1990s. This is only logical as they, not national governments, are in fact their true authors. Multistakeholder leadership proves truer in the global "enforcement" of SRHR than for any other UN "paradigm".

To implement the UN health objectives - chief among them SRHR - the UN Secretary General took the initiative, in 2010, independently from governments, to launch both a global strategy for women's and children's health and a multistakeholder movement to put this strategy into action. The movement, called Every Woman Every Child, is powerfully supported by the Global Financing Facility and is, according to the UN SG, in a momentum.

The UN Secretariat issued a new version of its strategy when the Sustainable Development Goals were adopted: The Global Strategy for Women's, Adolescents and Children's Health 2016-2030 - Survive, thrive, transform [GS 2015]. It is noteworthy that the updated version includes adolescents: the primary target of the global sexual revolution activists. 
The UN SG states that "we must build on what has worked in the past" and that the new strategy will "require new evidence-based approaches backed by innovative and sustainable financing mechanisms" [GS 2015: 5]. The very first example that the new strategy provides of "evidence-based" intervention packages for women is "sexual and reproductive health information and services". "Safe abortion" is also mentioned in that same short list of examples [GS 2015: 17]. "Sexual and reproductive health information and services" are again given as an example of evidence-based interventions for adolescents. "Too few adolescents have access to SRH services" [GS 2015: 17], reads the document.

Modern contraception is the first example the document provides of high returns on investment in women's and adolescents' health. The document dogmatically affirms that 225 million women worldwide have "an unmet need for family planning", and that $8 \%$ of maternal mortality is "attributable to unsafe abortion" [GS 2015: 25].

The global strategy advocates the promotion of laws, policies and social norms that advance SRHR and comprehensive sexuality education for adolescents and adults. This is all the more worrisome than the global strategy produces a comprehensive synthesis report annually.

The strategy incorporates the so-called "human rights-based approach to development cooperation" adopted by all UN agencies in 2003: "ensuring women and adolescent girls are aware of their rights" is fundamental [GS 2015: 38]. "Rights" in this context are obviously sexual and reproductive rights. The strategy also incorporates demographic objectives, linking them to economic and environmental factors: "Population stability would enhance economic sustainability and reduce the risks of climate change" [GS 2015: 19].

All major Panafrican health policies henceforth refer to the Global Strategy as well as to the Sustainable Development Goals, reflecting their alignment on their perspective as "normative", and their "fellow traveler" mindset: a tragic shame.

The systematic and successful integration of SRHR in all sectors of development and particularly in "universal health coverage" since Cairo is a matter of grave concern. The Global Strategy makes it plain that we are by now faced with a hermetic system, in which SRHR have become tightly connected to and inseparable from health financing, the training of health workforce, commodity 
supply, human rights education, monitoring mechanisms, women's, children's and adolescents' overall health, gender equality policies, educational contents, demographic concerns, climate change: it is all bundled together. SRHR are in all.

As regards commodity supply, the Global Strategy integrates the ten recommendations made by the so-called UN Commission on life-saving commodities to improve the availability of and access to thirteen allegedly "underutilized, low-cost, highimpact" [GS 2015: 56]. commodities. Three among these are components of SRHR: female condoms, contraceptive implants and emergency contraception. Let us note the degree of moral decadence of the UN, which considers these "life-saving" commodities! According to the Commission, these commodities would supposedly avert almost 230,000 maternal deaths. Part of the UN strategy is to support African countries in their efforts to improve distribution systems and create demand for these three commodities.

Another very worrisome development is the intricate political mechanisms now firmly in place and still expanding to enforce SRHR and monitor their implementation. Every sector is involved; not even "faith-based groups" can escape the watchdogs exercising pressure on all actors to align themselves and comply. The Global Strategy is provided with an "accountability framework" that harmonizes national and global monitoring, regional peer review, health sector reviews, human rights monitoring, gender assessments, parliamentary committees, citizen hearings, performance audits. Score cards are issued [GS 2015: 72]. It is a "unified framework" [GS 2015: 73]: no diversity of views is allowed.

\section{Panafrican policies and juridical instruments promoting SRHR adopted from 2002 to 2015}

Sadly enough, the African Union, the Panafrican institution launched in 2002, succumbed, from its onset, to the pressures of the global sexual revolution activists. This means that the African Union has become their springboard to align all African countries on "global norms".

Let us remind our readers the main policy and juridical instruments that were adopted since 2002 to implement the Cairo agenda on the African continent ${ }^{7}$.

\footnotetext{
7 The author exposed these in greater details in a booklet entitled "Twenty years of sexual and reproductive health and rights in Africa: Achievements of its transnational agents in African political institutions since Cairo, and their post-2015 strategy - Challenges for the Church".
} 
SRHR activists wasted no time in exerting their pressure first at the juridical level. The Maputo Protocol to the African Charter on Human and People's Rights on the Rights of Women in Africa, adopted in 2003 and already signed by 49, and ratified by 39 of the 54 African nations includes an article (article 14) on reproductive rights. Article 14 includes the right to abortion. The Protocol is the only instrument of international law that includes the right to abortion. In 2014, the African Commission adopted General Comment No. 2 on Article 14.1 (a), (b), (c) and (f) and Article 14. 2 (a) and (c) of the Protocol to the African Charter on Human and Peoples' Rights on the Rights of Women in Africa in 2014 (African Commission) so as to put maximum pressure on all African governments to, inter alia ${ }^{8}$, legalize abortion. African governments should have no illusions about the pressure they will increasingly be under.

At the policy level, SRHR agents then managed to obtain the adoption of a Continental Policy Framework for Sexual and Reproductive Health and Rights

8 According to General Comment, ratification of the Protocol would juridically commit state-parties to: Legalize or de-penalize medical abortion, or revisit restrictive laws to enlarge them; Provide "universal access" to the "whole range" of modern contraceptives (the observations make it clear that laws and policies "cannot restrict access to family planning/contraception on the basis of religious beliefs" (25) ; they also make clear that "the consent and involvement of third parties, including but not limited to, parents, guardians, spouses and partners, is not required when adult women and adolescent girls want to access family planning/contraception and safe abortion services in the cases provided for in the Protocol") (43); Remove "discriminatory laws, policies, procedures, practices" so that "women can effectively claim their reproductive freedom and the rights thereof, and enjoy the same" (21); "Develop and implement national action plans in order to mitigate the prevalence of unintended pregnancies" (20) ; Grant women the right to make personal decisions irrespective of "beliefs, traditions, values and cultural or religious practices", and "the right to question or ignore them" (24); "Remove impediments to the health services reserved for women [meaning, in the context of the General Comment, contraceptive and abortive "services"], including ideology or belief-based barriers. Administrative laws, policies and procedures of health systems and structures cannot restrict access to family planning/ contraception on the basis of religious beliefs" (25) ; Train healthcare providers and educators in reproductive health matters (28); Ensure that "available, accessible, acceptable and reliable information on contraceptive methods is provided, in printed form or by other means, such as the Internet, radio and television, mobile phone applications, and other telephone assistance service" (28); "Develop a national public health plan with comprehensive sexual and reproductive health services, protocols, guidelines and standards that are consistent with current evidence-based standards established by WHO and the committees responsible for ensuring compliance, by States" (30); Sensitize and educate communities, religious leaders, traditional chiefs and political leaders on women's sexual and reproductive rights (44) ; Guarantee the provision of "comprehensive information and education" on contraception, "safe abortion", "reproductive rights" for adolescents girls and young people (51); Integrate reproductive health in school programs (52), and sexual and reproductive rights in civic education programs (60); "Allocate adequate financial resources" for reproductive health (62), etc. 
(2007-2010). African ministers of health adopted it at the $2^{\text {nd }}$ African Union Conference of Health Ministers held in Gaborone, Botswana in October 2005. The "framework" was endorsed by African heads of states and governments in 2006. This alleged framework remains in vigor and the reference used in African health policies. At a special session of the African Union in Maputo in 2006, African Ministers of Health then adopted the Maputo Plan of Action on Sexual and Reproductive Health and Rights ${ }^{9}$ to implement the "framework".

The Maputo Protocol and its General Comment $\mathrm{N}^{\circ}$ 2, the Continental Policy Framework and the Maputo Plan of Action are unforgiving. Unless there is a rapid and strong moral awakening of African leaders and peoples, one does not see how Africa will resist the imposition of the neo-colonizers, their ready-made agenda enforced through the seduction of their "technical expertise" and powerful financial means.

The 2015-2063 SRHR African agenda: Maputo Plan of Action 2016-2030, Agenda 2063, and the Africa Health Strategy

Three key strategic documents of the African Union address SRHR on the continent for the coming years and decades. The first is The Maputo Plan of Action 2016-2030 for the Operationalization of the Continental Policy Framework for Sexual and Reproductive Health, subtitled "Universal Access to Comprehensive Sexual and Reproductive Health Services in Africa": it is an updated version of the 2006 Maputo Plan of Action. The second is Agenda 2063 - The Africa We Want, adopted by the African Union Commission in 2015 and defined as "a strategic framework for the socio-economic transformation of the continent over the next 50 years" and "a global strategy to optimize the use of Africa's resources for the benefit of all Africans". The third is The Africa Health Strategy.

The first document deals exclusively with SRHR, as its full title suggests. It is the driving strategy of SRHR agents operating in Africa, which basically equates with that of the International Planned Parenthood Federation and Cairo. The two other documents integrate the vision of the Maputo Plan. This imbrication shows the extent to which SRHR have successfully been integrated in mainstream development policies on the African continent.

The Maputo Plan of Action 2016-2030. The Maputo Plan of Action bases itself on an ideological dogma: "Health, especially sexual and reproductive health

9 The proposed budget for this plan of action was 16 Billion dollars. 
and reproductive rights is a precondition for and an outcome indicator of all aspects of sustainable development" [Maputo Plan: 10]. Hence it aims at prioritizing reproductive health "into continental, regional and national development plans" [Maputo Plan: 11]. The Plan recognizes the "relevance" of the continental policy framework adopted in 2005, which had established ten strategic interventions, among which: increasing resources to SRHR programmes; translating Cairo into national legislations and policies; expanding contraceptive use; reducing levels of unsafe abortion (understand: try and legalize abortion); ensuring access of adolescents and youth to SRHR. The revised Maputo Plan of Action builds on ten action areas among which: political commitment; health legislation; "investing in SRH needs of adolescents, youth and other vulnerable population"; "monitoring, reporting and accountability". The strategy insists on the necessity to build SRH and RR "into and on an effective health system". It sets "indicators for monitoring progress" [Maputo Plan: 8-9]. The conclusion of the Maputo Plan reads: "African leaders have a civic obligation to respond to the SRH needs and RR of their people" [Maputo Plan: 25].

Agenda 2063 - The Africa We Want. The document starts by a "We the people of Africa" declaration. It presents its underlying vision as rooted in "Pan Africanism" and "African Renaissance": Agenda 2063 is supposed to represent the voices of the African people, African aspirations, African identity, cultures and traditions. It spells out seven African aspirations, among which one reads: "Africa with a strong cultural identity, common heritage, values and ethics". Another aspiration is "An Africa whose development is people driven, relying on the potential offered by people" [Agenda 2063: 2]. What would make Agenda 2063 different from other continental policy document is that it would not be "the work of bureaucrats, but rather an Agenda driven by the voices of the African people indicating the Africa They Want” [Agenda 2063: note 1].

How shocking then to discover the inclusion and centrality, in this allegedly purely "African" strategic development framework, of reproductive health and rights! The expression is mentioned seven times. A central health objective of Agenda 2063 is the following: "By 2063, every citizen will have full access to affordable and quality health care services, universal access to sexual and reproductive health and rights information, and these services will be available to all women, including young women, adolescents, women with disability, those living with AIDS and all 
vulnerable groups"10. Let us note that this "full access" to SRHR is to be granted to every citizen, not matter the age and marital status: a forecast of the Panafrican sexual revolution.

The Africa Health Strategy. After the adoption of Agenda 2063 and based on it, the African Union Commission produced a continental health policy framework, the Africa Health Strategy 2016-2030 [AHS], supposed to provide "strategic direction to Africa's Member States in their efforts in creating better performing health sectors, recognizes existing continental commitments and addresses key challenges facing efforts to reduce the continent's burden of disease mainly by drawing on lessons learned and taking advantage of the existing opportunities" [AHS: 9].

The health policy is also based on the SDGs, the Sexual and Reproductive Health and Rights Continental Policy Framework and its extended Maputo Plan of Action (2016-2030), the Pharmaceutical Manufacturing Plan for Africa (PMPA), the Global Strategy for Women's, Children's and Adolescent Health 2016 - 2030. It is no surprise that the priority of its strategic objective \# 2 reads as follows: "ending preventable maternal, new born and child deaths and ensure equitable access to comprehensive, integrated sexual, reproductive, maternal, neonatal, child and adolescent services, including voluntary family planning" [AHS: 22].

10 Other mentions are: "No woman shall die in pregnancy. There shall be full access to integrated sexual and reproductive health care and institutional delivery for all women of reproductive age". "The commitments to integrate sexual and reproductive health and rights, family planning and HIV/AIDS services through reinforcing action on earlier commitments to enhance maternal, newborn and child health status, ensuring the integration necessary to facilitate synergies Health Policy Measures". "Ensure universal access to sexual and reproductive health rights, including to reduce maternal mortality rates and end preventable maternal morbidities, and to halt the spread of HIV/AIDS". "The number of girls out of school has dropped significant from 24 million in 2000 to 9 million in 2013. Furthermore, nearly half of the African countries have attained gender parity in primary school enrolment in 2012. However, these gains have not yet fully impacted on reducing inequalities between men and women, especially with respect to access and control of economic resources, as well as in terms of labour market participation or reproductive rights (maternal mortality and fertility)." Or "The continent cannot meet its ambitious goals under Agenda 2063 while it limits a dynamic segment of its society, which women represent, from realizing its full potential. Investing in women and girls and their integration into the labour market, alongside delayed marriage and child bearing and expanded access to education for girls, family planning and sexual and reproductive health rights, has been attributed as the driving forces behind the economic successes of the "Asian tigers"." 


\section{Conclusion}

Africa stands at a kairos. UN statistics reveal that the lifestyles and behaviors of African women and youth are changing and aligning themselves on the norms of the western sexual revolution of the 1960s and 70s. Panafrican policy documents, in particular in the areas of gender, health and education, manifest African political alignment along the ideological perspective of global governance. It is not out of "free choice" that Africa is going down that cultural and political route, but under the relentless pressure of the transnational sexual and reproductive health and reproductive rights lobby.

Yet is submission to this pressure a fatality? A fundamental mindset change amongst Africans and their political leaders seems to be in order. To the extent they behave as servile followers of global governance (out of naïveté, out of ignorance, out of corruption, whatever the reason...), they must decide to love themselves enough to check the neo-colonialist agenda against who they are and want to be as Africans. They must learn to govern themselves according to their own, family-centred values. This implies being more prudent before jumping on the bandwagon of alleged global "consensuses" and "partnerships". Incidentally, the power wielded by global governance also challenges any Northern government supportive of the family and life to encourage Africa to remain itself and self-govern.

A pressing policy priority for the continent is education. The IPPF-inspired "comprehensive sexuality education" programmes now imposed on African ministries of education, schools and youth groups promises to produce in Africa the same results as in the West. The choices made by today's generation of young Africans with regards to sexuality, marriage, family, life and morality will determine the future of the continent: Africa either remains itself, or loses itself. Just as one single generation produced the critical mass necessary for overturning an entire civilization in the West (the May 68 generation), so is this very generation of African children and young people absolutely critical.

Greater African self-knowledge and self-love, combined with a rigorous human and moral education, should be integrated in school curriculum. Africans must awake to who they are, to their responsibility as individuals and peoples in the world today. They alone can decide for integral human development, the only alternative to the moral decadence of the continent of life and the family. Genuine solidarity can take place once they themselves make that decision. 


\section{Bibliography}

Agenda 2063, African Union.

AHS, African Union Department of Social Affairs. Africa Health Strategy 2016-2030.

Francis Pope (2015), Laudatio Si'. Encyclical Letter Laudato Si' on Care for our Common Home.

Gaudium et spes (1965), Vatican II. Pastoral Constitution on the Church in the Modern World Gaudium et Spes.

GS (2015), Every Woman Every Child. The Global Strategy for Women's, Children's and Adolescents' Health (2016-2030). Sustainable Development Goals.

Maputo Plan of Action 2016-2030 for the Operationalization of the Continental Policy Framework for Sexual and Reproductive Health and Rights. Universal Access to Comprehensive Sexual and Reproductive Health Services in Africa.

Paul VI Pope (1968), Humanae Vitae, Encyclical Letter Humanae Vitae on the Regulation of Birth.

Peeters Marguerite A. (1995), IIS 7. October 13.

Peeters Marguerite A. (2012), Dialogue Dynamics. The globalization of the western cultural revolution. Key concepts, operational mechanisms.

Peeters Marguerite A., Dialogue Dynamics. Twenty years of "sexual and reproductive health and rights" in Africa. Achievements of its transnational agents in African political institutions since Cairo, and their post-2015 strategy. Challenges for the Church.

Suaudeau J., (2010), The contraception-abortion nexus, Dialogue Dynamics, http:// dialoguedynamics.com/content/forum-d-apprentissage/interviews-and-articles/ article/mons-jacques-suaudeau-on-the

WPP 2017, UN Department of Economic and Social Affairs. Population Division. World Population Prospects. The 2017 Revision. Key Findings and Advance Tables. UN NY 2017. 